ISSN 2079-4991

www.mdpi.com/journal/nanomaterials

Article

\title{
Magnetism of Amorphous and Nano-Crystallized Dc-Sputter-Deposited MgO Thin Films
}

\author{
Sreekanth K. Mahadeva ${ }^{1,2}$, Jincheng Fan ${ }^{1,3}$, Anis Biswas ${ }^{1,4}$, K. S. Sreelatha ${ }^{2,5}$, Lyubov Belova ${ }^{1}$ \\ and K. V. Rao ${ }^{1, *}$
}

1 Department of Materials Science, Tmfy-MSE, The Royal Institute of Technology, Stockholm SE100 44, Sweden; E-Mails: skm@kth.se (S.K.M.); fanjincheng2006@yahoo.com.cn (J.F.); biswas.anis@gmail.com (A.B.); lyuba@kth.se (L.B.)

2 Department of Physics, Amrita Vishwa Vidyapeetham University, Amritapuri Campus, Kollam, Kerala 690525, India; E-Mail: kssreelatha@yahoo.com

3 School of Materials and Engineering, Anhui University of Technology, Maanshan 243002, China

4 Department of Physics, University of South Florida, Tampa, FL 33620, USA

5 Department of Physics, Government College, Kottayam, Kerala 686013, India

* Author to whom correspondence should be addressed; E-Mail: rao@kth.se; Tel./Fax: +46-0-8790-7771.

Received: 13 June 2013; in revised form: 20 July 2013 / Accepted: 26 July 2013 /

Published: 7 August 2013

\begin{abstract}
We report a systematic study of room-temperature ferromagnetism (RTFM) in pristine $\mathrm{MgO}$ thin films in their amorphous and nano-crystalline states. The as deposited dc-sputtered films of pristine $\mathrm{MgO}$ on $\mathrm{Si}$ substrates using a metallic $\mathrm{Mg}$ target in an $\mathrm{O}_{2}$ containing working gas atmosphere of $\left(\mathrm{N}_{2}+\mathrm{O}_{2}\right)$ are found to be X-ray amorphous. All these films obtained with oxygen partial pressure $\left(\mathrm{P}_{\mathrm{O} 2}\right) \sim 10 \%$ to $80 \%$ while maintaining the same total pressure of the working gas are found to be ferromagnetic at room temperature. The room temperature saturation magnetization $\left(\mathrm{M}_{\mathrm{S}}\right)$ value of $2.68 \mathrm{emu} / \mathrm{cm}^{3}$ obtained for the $\mathrm{MgO}$ film deposited in $\mathrm{P}_{\mathrm{O} 2}$ of $10 \%$ increases to $9.62 \mathrm{emu} / \mathrm{cm}^{3}$ for film deposited at $\mathrm{P}_{\mathrm{O} 2}$ of $40 \%$. However, the $\mathrm{M}_{\mathrm{S}}$ values decrease steadily for further increase of oxygen partial pressure during deposition. On thermal annealing at temperatures in the range 600 to $800{ }^{\circ} \mathrm{C}$, the films become nanocrystalline and as the crystallite size grows with longer annealing times and higher temperature, $\mathrm{M}_{\mathrm{S}}$ decreases. Our study clearly points out that it is possible to tailor the magnetic properties of thin films of $\mathrm{MgO}$. The room temperature ferromagnetism in $\mathrm{MgO}$ films is attributed to the presence of $\mathrm{Mg}$ cation vacancies.
\end{abstract}


Keywords: room temperature ferromagnetism; $\mathrm{Mg}$ vacancy; magnetron sputtering; $\mathrm{O}_{2}$ content; annealing

\section{Introduction}

Magnesium Oxide with rocksalt-structure has been extensively investigated due to its exceptional properties, such as chemical inertness, high electrical resistivity, optical transparency, and low thermal conductivity [1-4]. $\mathrm{MgO}$ have been used widely in technology and industry, such as an insulating layer in magnetic tunnel junctions, insulating coating of electrodes in magneto hydrodynamic devices, electrodes in plasma technology, Josephson junctions and catalysis [5-11]. Currently, the role of defective sites in $\mathrm{MgO}$ films is a subject of intense research. Such defective sites, present in $\mathrm{MgO}$, can introduce new electronic states, resulting in several intriguing optical, electronic and magnetic phenomena [12,13]. For example, room temperature ferromagnetism (RTFM) can arise in a MgO thin film due to the presence of point defects, which opens new possibilities for spin photonic device application $[14,15]$. In an earlier study, Ferrari et al. investigated the magnetic properties of $\mathrm{MgO}$, extensively and suggested that magnetic moment appeared in the local environment of low coordinated $\mathrm{O}$ atoms at the surface [16]. It has also been pointed out that presence of nitrogen can influence magnetic property of $\mathrm{MgO}$ [17,18]. Although there are many theoretical and experimental studies regarding $\mathrm{RTFM}$ in $\mathrm{MgO}$, there is still a lack of understanding about the origin of such phenomenon [19-22].

The main objective of the present study is to obtain a detailed insight into the role of defects and processing parameters on RTFM in MgO. In this regard, we have investigated the relation between the RTFM, the crystallinity, and $\mathrm{Mg}$ vacancies in the $\mathrm{MgO}$ films, by combining the magnetic measurements with the structural and composition analyses as a function of thermal treatment for different periods of time. Our comprehensive study reveals that the defects related to $\mathrm{Mg}$-vacancies in the films are mainly responsible for RTFM in the materials.

\section{Results and Discussion}

\subsection{Structural Properties of Films}

Figure 1 shows the X-ray diffraction (XRD) patterns of $\mathrm{MgO}$ films deposited with different $\mathrm{P}_{\mathrm{O} 2}$ in the working gas. Peaks related to $\mathrm{MgO}$ were not observed in the XRD patterns of the samples indicating that the films are mostly amorphous in the as-grown state. Large lattice mismatch (22.4\%) between $\mathrm{MgO}(0.4213 \mathrm{~nm})$ and $\mathrm{Si}(0.543 \mathrm{~nm})$ and a large difference in thermal expansion coefficients $\left(\mathrm{MgO}: 13.5 \times 10^{-6} /{ }^{\circ} \mathrm{C}\right.$, Si: $4.0 \times 10^{-6} /{ }^{\circ} \mathrm{C}$ ) hinder the possible epitaxial growth of $\mathrm{MgO}$ on $\mathrm{Si}$ substrates $[23,24]$. The film deposited with the $\mathrm{P}_{\mathrm{O} 2}$ of $10 \%$ shows a broad peak at about $42^{\circ}$. However, the peaks at about $42.9^{\circ}$ and $62.3^{\circ}$, corresponding to (200) and (220) of $\mathrm{MgO}$, respectively, are clearly visible in XRD patterns of thermally annealed samples (Figures 2 and 3), indicating the development of crystallinity after annealing treatment. Such a development of crystallinity can be attributed to the increasing mobility of the atoms caused by annealing [2]. The average crystallite size for the samples 
was estimated by using Scherrer's formula from (200) peaks and is found to be $4.3 \mathrm{~nm}$ for the as grown film, deposited at $\mathrm{O}_{2}$ partial pressure of $10 \%$ and after the thermal treatment the grain size increases up to $\sim 20 \mathrm{~nm}$. The variation of grain size with annealing temperature and time is shown in the Figure 4. It should be noted, the films prepared in other oxygen partial pressure are predominantly amorphous in nature (Figure 1). There exists no visible peak in XRD pattern of those films. Therefore, it is not possible to evaluate grain size using Scherrer's formula from XRD data for those films. The $\mathrm{X}$-ray amorphous nature of this film may be indication of very small grain size of the films.

Figure 1. X-ray diffraction (XRD) patterns of $\mathrm{MgO}$ films deposited in different oxygen partial pressures: (a) $10 \%$, (b) $20 \%$, (c) $40 \%$, and (d) $80 \%$.

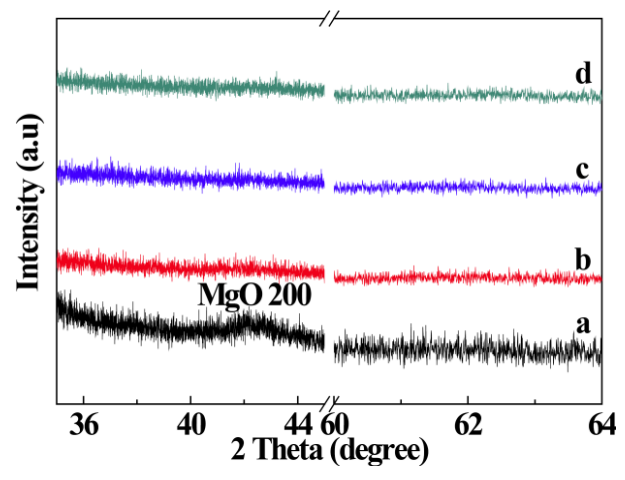

Figure 2. The $\mathrm{XRD}$ patterns of the (a) as-grown film deposited at $\mathrm{P}_{\mathrm{O} 2}$ of $10 \%$, annealed for $1 \mathrm{~h}$ at $(\mathbf{b}) 600{ }^{\circ} \mathrm{C}$, (c) $700{ }^{\circ} \mathrm{C}$, (d) $800{ }^{\circ} \mathrm{C}$ respectively.

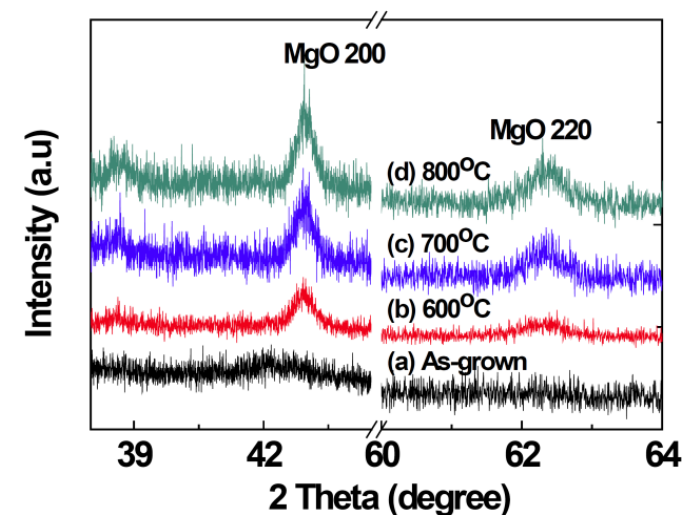

Figure 3. The XRD patterns of the (a) as-grown film deposited at $\mathrm{P}_{\mathrm{O} 2}$ of $10 \%$ annealed at $700{ }^{\circ} \mathrm{C}$ for (e) $1 \mathrm{~h}$, (f) $2 \mathrm{~h}$ respectively.

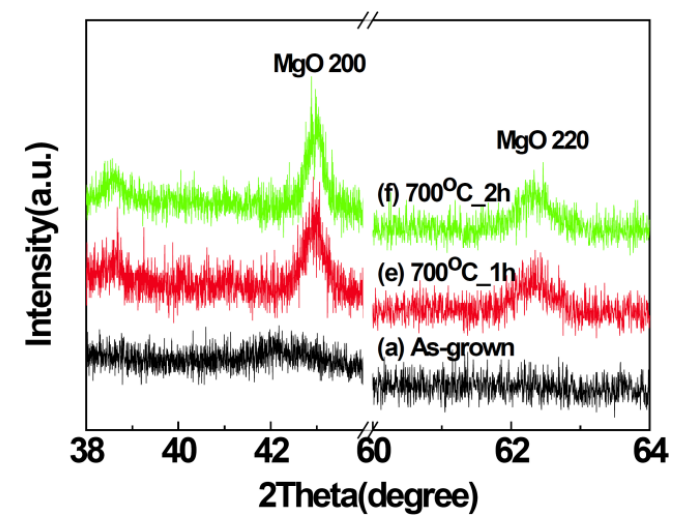


Figure 4. The variation of grain size with $1 \mathrm{~h}$ anneals at various temperatures (inset: the variation of grain size with annealing time).

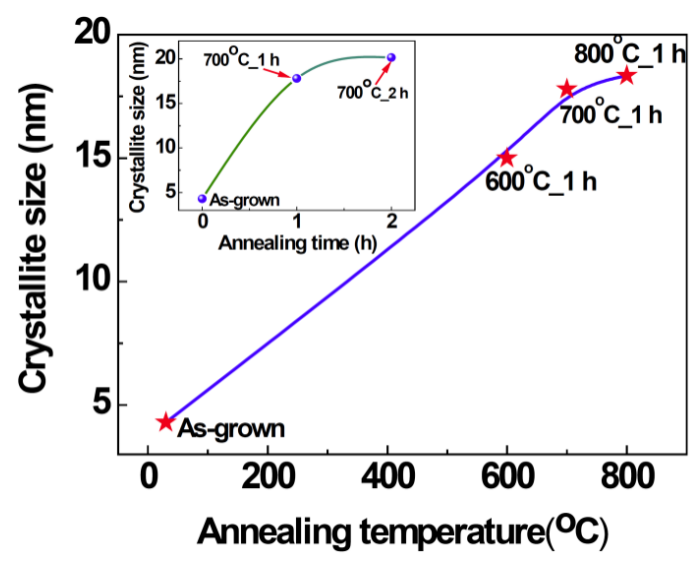

\subsection{Scanning Electron Microscopy (SEM)/Focused Ion Beam (FIB) and Energy Dispersive} $X$-Ray Analyses

The cross-section of $\mathrm{MgO}$ films were analyzed by FIB, the Figure 5 shows the typical cross-section of as-grown and annealed $\left(800{ }^{\circ} \mathrm{C}\right) \mathrm{MgO}$ films and the thickness of the films found to be in the range of $\sim 80-250 \mathrm{~nm}$. Figure 6 shows the film thickness as function of $\mathrm{P}_{\mathrm{O} 2}$. It is clear that the film thickness decreases with the increase of $\mathrm{P}_{\mathrm{O} 2}$. In the sputtering process, plasma of non-reactive ions is created by a potential difference inside a vacuum chamber, which falls on the target material and breaks the atoms and are then deposited on the substrate. When the $\mathrm{P}_{\mathrm{O} 2}$ increases the formation of the number of non-reactive ions decreases and consequently results in the decrease of the film thickness. It can be seen that the as-grown films were amorphous and after annealing, the structure of the films was improved and the well-shaped uniform grains were formed, which is consistent with XRD results (Figure 2). Typical SEM images of the films are shown in Figure 7, which clearly indicates the increase of grain size with increase of annealing temperature. Also note that the thickness of the films decreased after annealing in our experiments, suggesting that the films become denser and probably contain fewer defects.

Figure 5. A typical cross-section of $\mathrm{MgO}$ films, obtained using Focused Ion Beam (FIB), in their (a) as-grown, and (b) annealed at $800^{\circ} \mathrm{C}$ in air for $1 \mathrm{~h}$ states.

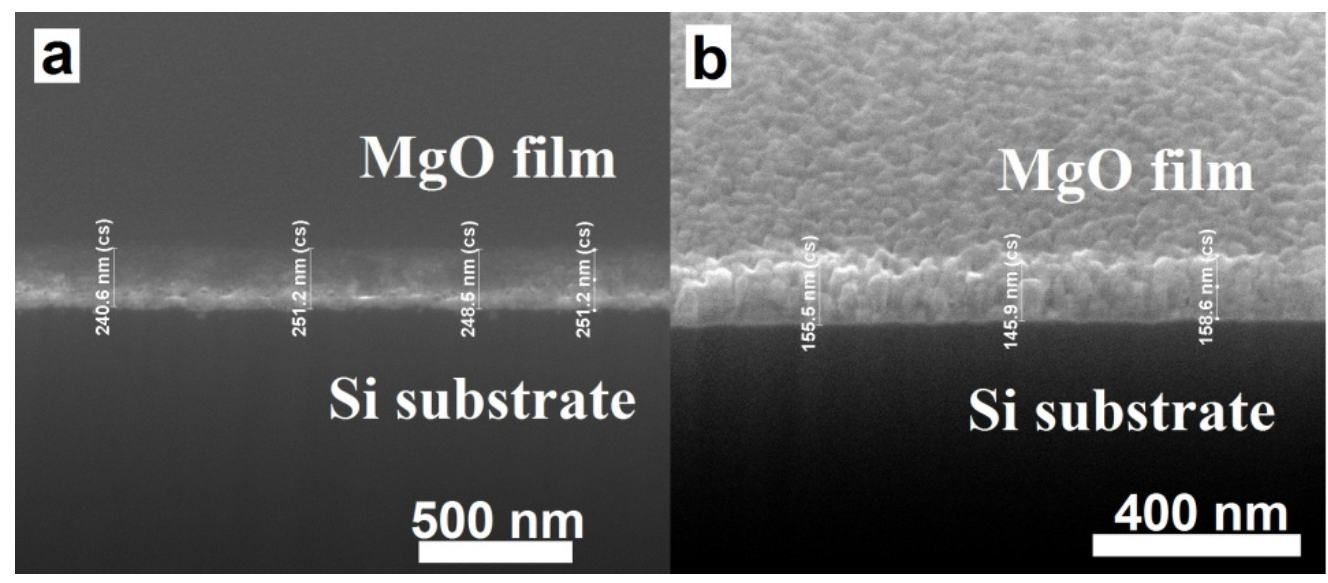


Figure 6. The film thickness as a function of oxygen partial pressure $\left(\mathrm{P}_{\mathrm{O} 2}\right)$.

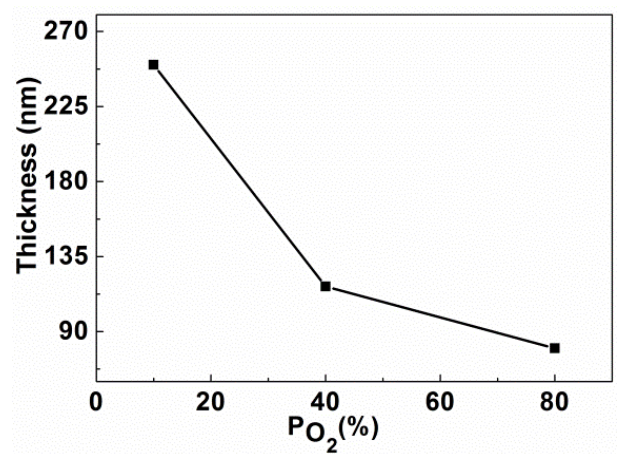

Figure 7. Scanning Electron Microscopy (SEM) images of (a) as-grown, and annealed films at (b) $700{ }^{\circ} \mathrm{C}$, and (c) $800^{\circ} \mathrm{C}$ for $1 \mathrm{~h}$ respectively.

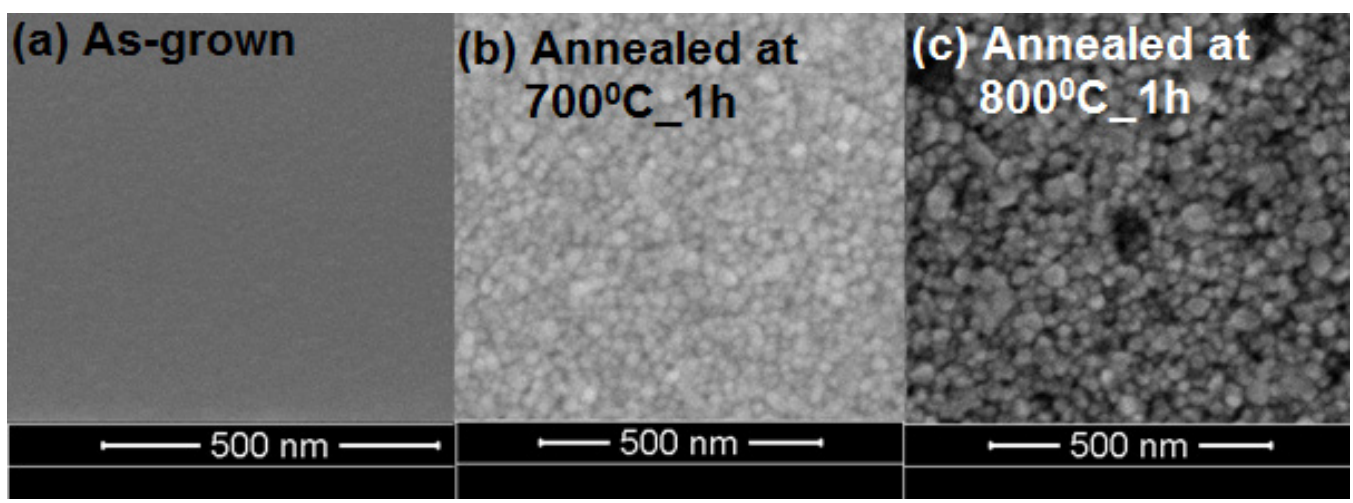

Energy dispersive spectroscopic (EDS) was used to analyze the compositions of $\mathrm{MgO}$ films. Figure 8 shows the typical EDS spectrum of $\mathrm{MgO}$ film deposited with the $\mathrm{O}_{2}$ content of $10 \%$. Only $\mathrm{Si}, \mathrm{Mg}$, and $\mathrm{O}$ peaks were detected, indicating the absence of any form of transition metal contamination in the films within the limits of detection. Obviously, the observed peak of Si should be ascribed to the substrates. The inset of Figure 8 shows the corresponding atomic $\%$ of $\mathrm{Mg}$, and $\mathrm{O}$. The ratio of $\mathrm{O}$ to $\mathrm{Mg}$ was $\sim 1.8(>1)$, which suggests that there may be a lot of deficiency $\mathrm{Mg}$ vacancies in the $\mathrm{MgO}$ films.

Figure 8. The energy dispersive spectroscopic (EDS) spectrum for $\mathrm{MgO}$ film deposited with $\mathrm{O}_{2}$ content of $10 \%$ in the working gas.

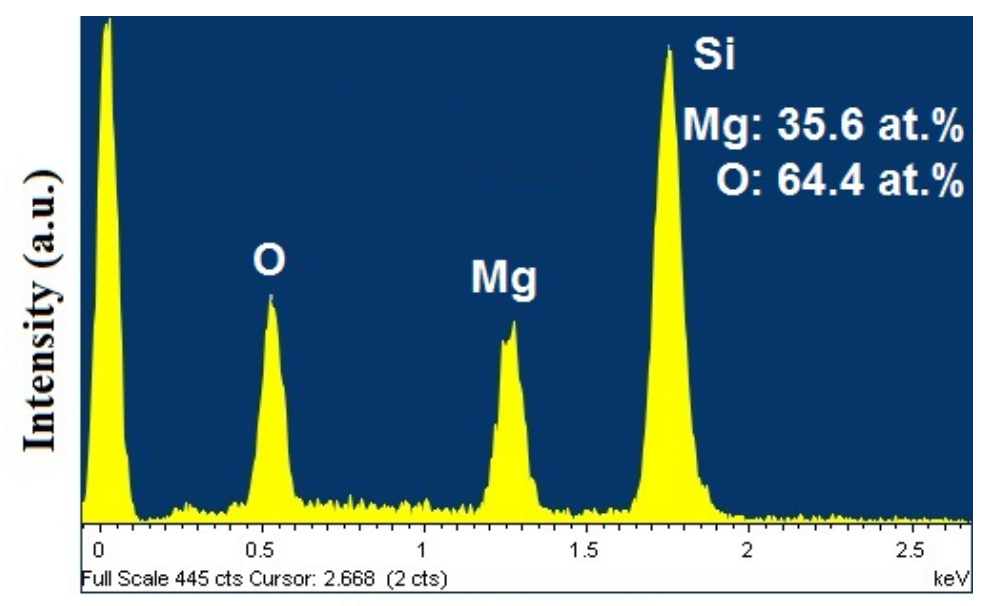

Energy (keV) 


\subsection{Magnetic Properties}

Prior to the magnetic measurement of the thin films, to rule out the possibility of the magnetic contamination in the $\mathrm{Mg}$ target, we have investigated a thick film $(\sim 1.2 \mu \mathrm{m})$ of the target by using Energy Dispersive X-ray spectroscopy to confirm the absence of any impurity and also studied M-H loops of the thick film. None of these studies exhibited any possible existence of even a signature of ferromagnetism. Energy Dispersive X-ray spectroscopy study reveals presence of $\mathrm{Mg}(92.7 \%)$ and $\mathrm{O}(7.3 \%)$ in this film. Thus, the ferromagnetic property of the films is intrinsic. Both the EDS and SQUID data of the thick Mg film $(\sim 1.2 \mu \mathrm{m})$ of the target are presented in the Figure $9 \mathrm{a}, \mathrm{b}$, respectively.

Figure 9. The (a) EDS spectrum and (b) M-H loop for the $1.22 \mu \mathrm{m}$ thick Mg film.
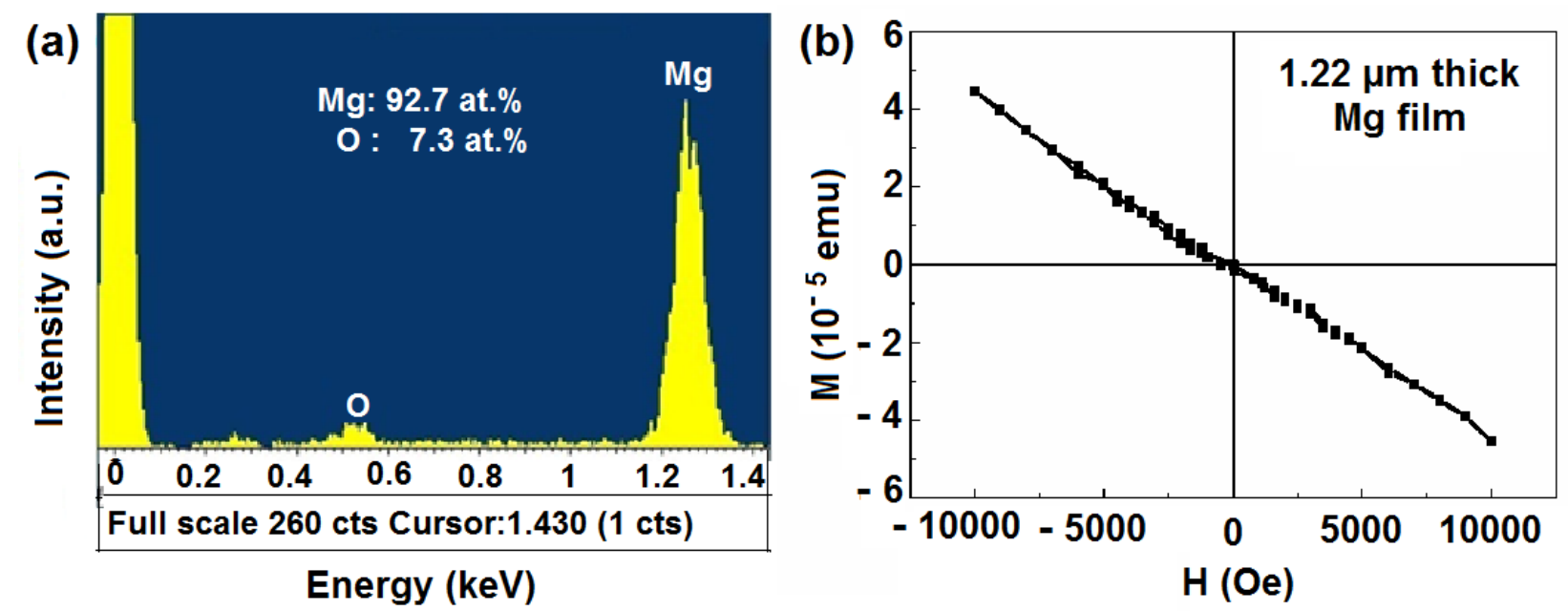

One may doubt whether such a large $\mathrm{M}_{\mathrm{S}}$ value is the property of $\mathrm{MgO}$ films or it arises from small amount of magnetic contamination present in the sample. To rule out such a possibility, the target as well as the substrates were checked by EDS analyses which only confirmed the absence of any impurity. We also studied $\mathrm{M}-\mathrm{H}$ curve of the parts of targets and substrates and found no evidence of possible ferromagnetism. Thus, the ferromagnetic property we observe in the thinner films is intrinsic.

We have studied the effect of thermal annealing on the magnetic properties of $\mathrm{MgO}$ films, systematically. The film, deposited at $10 \%$ oxygen partial pressure, was chosen for this purpose as it exhibits some signature of (200)-peak in its XRD pattern. Thermal treatment was performed for the sample deposited in $\mathrm{O}_{2}$ content of $10 \%$ at 600,700 and $800{ }^{\circ} \mathrm{C}$ respectively in air for $1 \mathrm{~h}$. RTFM was observed in the as-grown and annealed $\mathrm{MgO}$ films, which is consistent with previous reports of magnetism in undoped oxides, such as $\mathrm{MgO}, \mathrm{ZnO}, \mathrm{TiO}_{2}, \mathrm{In}_{2} \mathrm{O}_{3}$ and $\mathrm{HfO}_{2}$ [19,25-28]. Figures 10 and 11 show the magnetic field dependence of magnetization $(\mathrm{M}(\mathrm{H}))$ curves at room temperature for as-grown and annealed films (deposited at $\mathrm{P}_{\mathrm{O} 2} \sim 10 \%$ ) after carrying out the standard diamagnetic corrections for the substrate effects. In a recent study, Gao et al. considered that $\mathrm{V}_{\mathrm{Mg}}$ could introduce strong ferromagnetism in $\mathrm{MgO}$ films and the ferromagnetism depended on the $\mathrm{V}_{\mathrm{Mg}}$ concentration in the $\mathrm{MgO}$ films [19].

Annealing resulted in a reduction in the $\mathrm{M}_{\mathrm{S}}$ value from $\sim 2.69$ to $1.18 \mathrm{emu} / \mathrm{cm}^{3}$ (inset, Figure 10). The decrease could tentatively be ascribed to the reduction of $\mathrm{V}_{\mathrm{Mg}}$ in $\mathrm{MgO}$ films due to annealing. The contribution of one $\mathrm{V}_{\mathrm{Mg}}$ in the total magnetic moment is $1.9 \mu \mathrm{B}$ for $\mathrm{MgO}$ [19]. Therefore, the decrease 
in the magnetization of $1.5 \mathrm{emu} / \mathrm{cm}^{3}$ actually corresponds to a reduced number of $\mathrm{V}_{\mathrm{Mg}}$ of $8.5 \times 10^{19} / \mathrm{cm}^{3}$ in the annealed $\mathrm{MgO}$ films. A similar phenomenon was also observed for $\mathrm{MgO}$ films annealed at $700{ }^{\circ} \mathrm{C}$ for different times (Figure 11) resulting in a reduction of the $\mathrm{M}_{\mathrm{S}}$ value of the sample from $\sim 2.69$ to $1.9 \mathrm{emu} / \mathrm{cm}^{3}$. Inset shows the $\mathrm{M}_{\mathrm{S}}$ values as a function of annealing time.

Figure 10. Room-temperature $\mathrm{M}-\mathrm{H}$ loops for the as-grown (a), and annealed $\mathrm{MgO}$ films in air for $1 \mathrm{~h}$ at (b) $600{ }^{\circ} \mathrm{C}$, (c) $700{ }^{\circ} \mathrm{C}$, and (d) $800{ }^{\circ} \mathrm{C}$, respectively. The (M-H) loops are shown after correcting for the diamagnetic contribution from Si-substrate. The Inset shows the $\mathrm{M}_{\mathrm{S}}$ values at room-temperature $(\mathrm{RT})$ observed as a function of annealing temperature.

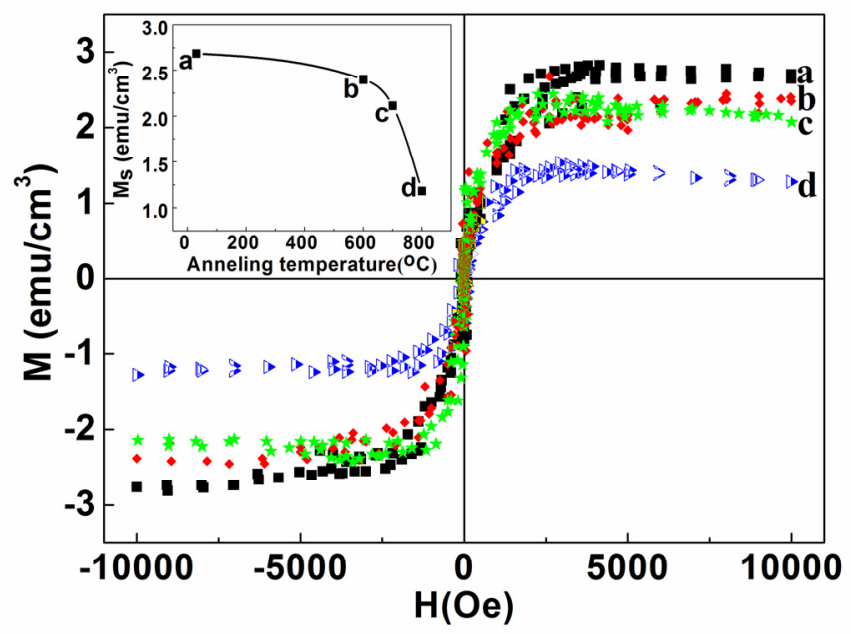

Figure 11. The room temperature $\mathrm{M}-\mathrm{H}$ of the as-grown (a), and annealed $\mathrm{MgO}$ Films at $700{ }^{\circ} \mathrm{C}$ for $1 \mathrm{~h}(\mathbf{b})$ and $2 \mathrm{~h}(\mathbf{c})$ respectively. The $(\mathrm{M}-\mathrm{H})$ loops are shown after correcting for the diamagnetic contribution from Si-substrate. Inset shows the $\mathrm{M}_{\mathrm{S}}$ values as a function of annealing time.

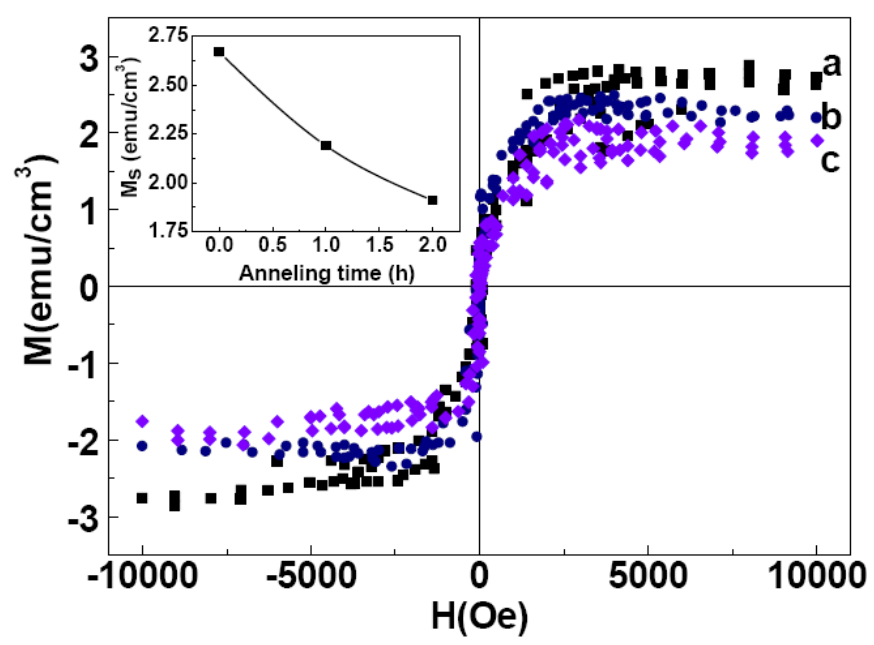

By investigating the XRD patterns of the $\mathrm{MgO}$ films before and after annealing, it can be inferred that the crystallinity grows in the films due to the annealing in air, as shown in the Figures 2 and 3. Consequently, the sharp decrease of $\mathrm{M}_{\mathrm{S}}$ at room temperature for the sample after annealing could be attributed to the increased crystallinity. On the other hand, this result confirms that magnetism in those 
$\mathrm{MgO}$ films is surely intrinsic rather than from any other transition metal contaminations [29]. The atmosphere during annealing may not only produce cation vacancies but also improve the crystallinity of the samples.

In order to understand the origin of the ferromagnetism (FM) observed in $\mathrm{MgO}$ films more clearly we also investigated the effect of oxygen partial pressure during deposition on the magnetization of $\mathrm{MgO}$ films at room temperature (RT). Figure 12 shows the $\mathrm{M}-\mathrm{H}$ loops measured at room temperature for $\mathrm{MgO}$ films deposited with the various $\mathrm{P}_{\mathrm{O} 2}$ in working gas. Inset of the Figure 12 shows $\mathrm{M}_{\mathrm{S}}$ as a function of $\mathrm{P}_{\mathrm{O} 2}$ in working gas. The results indicates that $\mathrm{P}_{\mathrm{O} 2}$ in working gas plays an important role to determine the magnetic properties of $\mathrm{MgO}$ films and ferromagnetism may originate from the defects at the cation sites, which is consistent with the theoretical results [19,30]. Initially, the increase in $\mathrm{O}_{2}$ content of the working gas increases the ratio of $\mathrm{O} / \mathrm{Mg}(>1)$, which could result in the enrichment of $\mathrm{V}_{\mathrm{Mg}}$ in the films and consequently the enhancement of $\mathrm{M}_{\mathrm{S}}$ is observed. However, further increase of $\mathrm{O}_{2}$ content may form O-related defects, such as oxygen interstitial $\left(\mathrm{O}_{\mathrm{i}}\right)$ and oxygen antisite $\left(\mathrm{O}_{\mathrm{Mg}}\right)$. These defects would break up the long range ferromagnetic chains and lead to lower net magnetization in the films.

Figure 12. The room temperature (M-H) loops for as-deposited $\mathrm{MgO}$ films with different $\mathrm{O}_{2}$ contents in the working gas: (a) $10 \%$, (b) $20 \%$, (c) $40 \%$, (d) $80 \%$. The loops are shown after correcting for the diamagnetic contribution from Si-substrate. Inset: dependence of room temperature $\mathrm{M}_{\mathrm{S}}$ values for films deposited under different $\mathrm{P}_{\mathrm{O} 2}$ in the working gas.

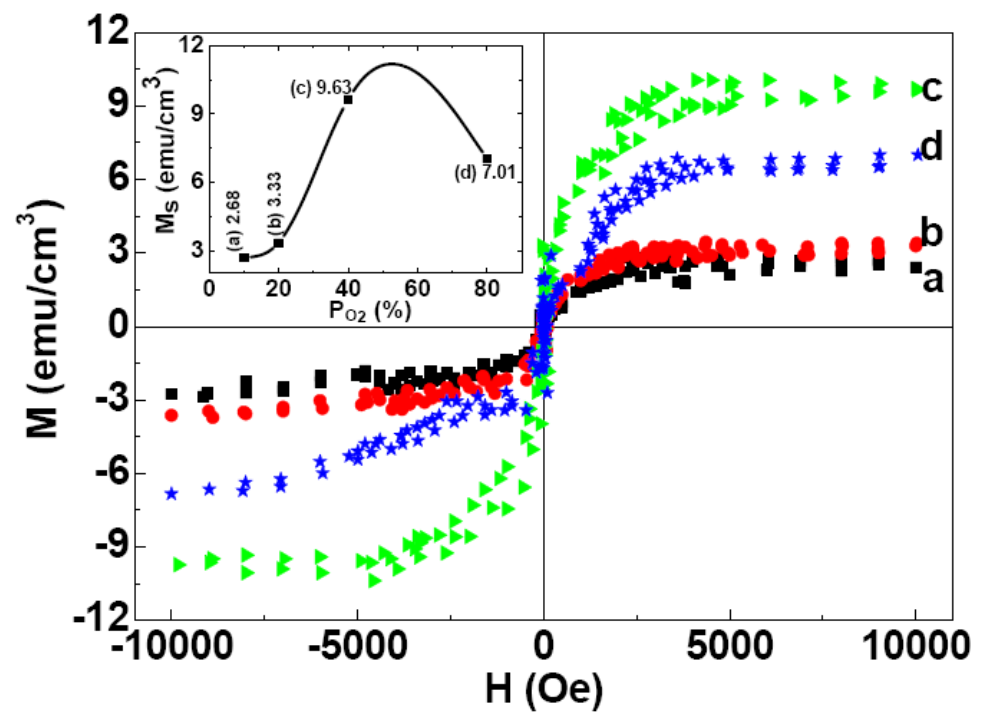

Figure 13 shows the $\mathrm{M}_{\mathrm{S}}$ values observed as a function of film thickness for as-deposited $\mathrm{MgO}$ films with different $\mathrm{O}_{2}$ contents. The $\mathrm{M}_{\mathrm{S}}$ of the films increases with the film's thickness and then decreases, which may be due to the increase in $\mathrm{V}_{\mathrm{Mg}}$ concentration at first and then due to the decrease of this concentration when the defects coalescence in thicker films due to the changes in the separation distance between the defects and also because of the decreasing strain as films become thicker in the case of crystalline films.

It should be noted that the obtained $\mathrm{M}_{\mathrm{S}}$ value for the films was low at lower oxygen content, indicating that the ferromagnetism does not arise from oxygen vacancy. Hence, the ferromagnetic 
ordering arises primarily due to the presence of cation vacancy, $\left(\mathrm{V}_{\mathrm{Mg}}\right)$. Obviously the amorphous oxides contains more defects in comparison with its crystalline counterpart. Since the RTFM is defect induced, it must be enhanced when the oxides are in the amorphous state as observed in the present case. Thus, the oxygen content in sputtering and annealing conditions are important factors in determining the RTFM in oxide thin films. These two factors are competitive and, in turn determine the nature and concentration of defects. Photoluminescence, electron nuclear double resonance, or positron annihilation techniques may be also useful to understand role of defects on RTFM in these films.

Figure 13. The $\mathrm{M}_{\mathrm{S}}$ value as a function of film thickness for as-deposited $\mathrm{MgO}$ films in an ambience of different $\mathrm{O}_{2}$ contents.

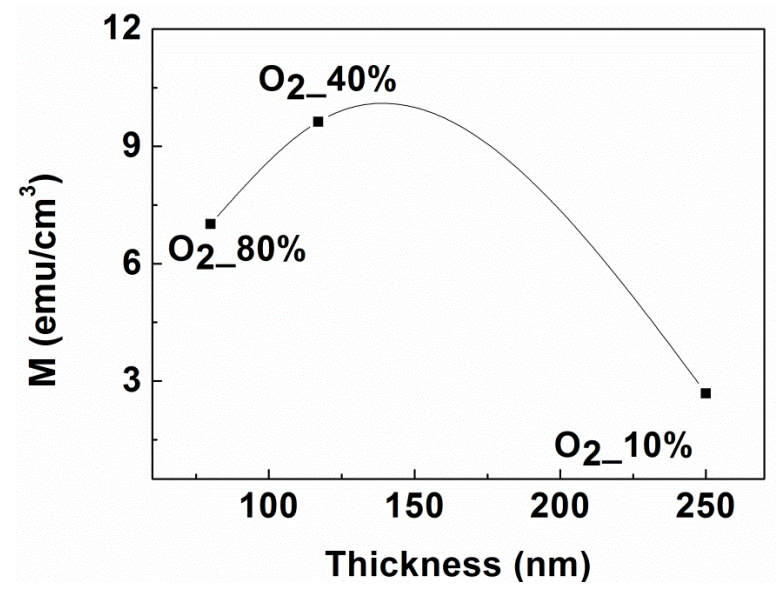

\section{Experiment}

\subsection{Fabrication of $\mathrm{MgO}$ Thin Films}

$\mathrm{MgO}$ films were deposited on $\mathrm{Si}$ substrates at room temperature by reactive $\mathrm{DC}$ magnetron sputtering using $99.99 \%$ pure $\mathrm{Mg}$ metallic target in a well-controlled $\left(\mathrm{O}_{2}+\mathrm{N}_{2}\right)$ atmosphere. The $\mathrm{Si}$ substrates were etched with hydro fluoric acid (HF) to remove surface native oxide $\left(\mathrm{SiO}_{2}\right)$, and then were cleaned in the ultrasonic baths of acetone, isopropanol and de-ionized water, and blown dried in nitrogen. The vacuum chamber was evacuated to a base of $10^{-3} \mathrm{~Pa}$. Prior to the films' growth, the $\mathrm{Mg}$ target was cleaned by sputtering it for $30 \mathrm{~min}$. $\left(\mathrm{N}_{2}+\mathrm{O}_{2}\right)$ maintained at $0.15 \mathrm{~Pa}$ was used as the working gas. $\mathrm{N}_{2}$ and $\mathrm{O}_{2}$ were introduced into the chamber via two digital mass flow meters. During deposition, the oxygen partial pressure $\left(\mathrm{P}_{\mathrm{O} 2}=\right.$ oxygen pressure/total pressure of oxygen and nitrogen) was kept at $10 \%, 20 \%, 40 \%$, and $80 \%$ of the total pressure, respectively. In order get an appropriate film thickness of the $\mathrm{MgO}$ films in this study were deposited for three hours with the DC power of $\sim 55 \mathrm{~W}$. Thermal treatment performed in air for the sample deposited with the $\left(\mathrm{P}_{\mathrm{O} 2}\right) 10 \%$ at 600,700 and $800{ }^{\circ} \mathrm{C}$ respectively for $1 \mathrm{~h}$ and $700{ }^{\circ} \mathrm{C}$ for $2 \mathrm{~h}$.

\subsection{Characterization Techniques}

The structure of $\mathrm{MgO}$ films was characterized by X-ray diffraction (XRD; Siemens D5000, Siemens, Munich, Germany) with $\mathrm{Cu} \mathrm{K \alpha}(\lambda=1.5405 \AA)$ radiation. The thickness of the films was 
determined from the cross-section analysis by a Dual-Beam UHR SEM/FIB system (FEI Nova 600 Nanolab; NanoPort, Eindhoven, The Netherlands). Energy dispersive spectroscopic (EDS, Oxford Instruments, Abingdon, UK) analyses were carried out to investigate the compositions of the films. The magnetic properties of $\mathrm{MgO}$ films were measured at room temperature by using a commercial SQUID magnetometer (Quantum Design Inc., San Diego, CA, USA).

\section{Conclusions}

$\mathrm{MgO}$ films were grown on Si substrates by direct current (DC) sputtering from a metallic $\mathrm{Mg}$ target with various $\mathrm{O}_{2}$ contents in working gas, and the effects of thermal annealing on the structural and magnetic properties were investigated. Our results reveal that there exists a close correlation between the room temperature ferromagnetism, the crystallinity, and the magnesium vacancy concentrations in the $\mathrm{MgO}$ thin films. All as-grown films were found to be amorphous most likely due to the large lattice mismatch between $\mathrm{MgO}$ and $\mathrm{Si}$ substrate. After annealing, the films became crystalline and the $\mathrm{M}_{\mathrm{S}}$ values decreased. The origin of the RTFM could be attributed to the $\mathrm{Mg}$ cation vacancies. The $\mathrm{P}_{\mathrm{O} 2}$ in working gas plays an important role to determine the $\mathrm{M}_{\mathrm{S}}$ value of as-grown $\mathrm{MgO}$ films. When $\mathrm{P}_{\mathrm{O} 2}$ increased from $10 \%$ to $80 \%, \mathrm{M}_{\mathrm{S}}$ values initially increased up to $\mathrm{P}_{\mathrm{O} 2}$ of $40 \%$ and then decreased at higher oxygen content in the working gas. EDS results show that the ratio of $\mathrm{O} / \mathrm{Mg}$ in $\mathrm{MgO}$ films is greater than 1, indicating the presence of high density of $\mathrm{Mg}$ vacancies in $\mathrm{MgO}$ films. Furthermore, we have found that less crystallinity can increase the ferromagnetism of $\mathrm{MgO}$ thin films due to larger amounts of $\mathrm{Mg}$ vacancies. Our results not only demonstrate an important approach to obtain room temperature ferromagnetic $\mathrm{MgO}$ films but also help to understand the origin of ferromagnetism in MgO films.

\section{Acknowledgements}

We thanks to Anastasia Riazanova for her help with SEM/FIB images for some of our samples. The work was supported by the Swedish funding Agencies: VINNOVA, Hero-M Centre of Excellence at KTH. Sreekanth K. Mahadeva acknowledges a graduate study fellowship funded by the India 4EU Erasmus Mundus External Cooperation Window program. Jincheng Fan and Anis Biswas acknowledge the Carl Trygg's Foundation in Sweden for a post-doctoral Scholarship.

\section{Conflict of Interest}

The authors declare no conflict of interest.

\section{References}

1. Renaud, G. Oxide surfaces and metal/oxide interfaces studied by grazing angle incidence X-ray scattering. Surf. Sci. Rep. 1998, 32, 1-90.

2. Cáceres, D.; Vergara, I.; González, R. Microstructural characterization of $\mathrm{MgO}$ thin films grown by radio-frequency sputtering. Target and substrate-temperature effect. J. Appl. Phys. 2003, 93, 4300-4305. 
3. Balcells, L.I.; Beltrán, J.I.; Martíne-Boubeta, C.; Konstantinović, Z.; Arbiol, J.; Martinez, B. Aging of magnetic properties in MgO films. Appl. Phys. Lett. 2010, 97, 252503:1-252503:3.

4. Nagashima, K.; Yanagida, T.; Tanaka, H.; Kawai, T. Epitaxial growth of MgO nanowires by pulsed laser deposition. J. Appl. Phys. 2007, 101, 124304:1-124304:4.

5. Ikeda, S.; Miura, K.; Yamamoto, H.; Mizunuma, K.; Gan, H.D.; Endo, M.; Kanai, S.; Hayakawa, J.; Matsukura, F.; Ohno, H. A perpendicular-anisotropy CoFeB-MgO magnetic tunnel junction. Nat. Mater. 2010, 9, 721-724.

6. Parkin, S.S.P.; Kaiser, C.; Panchula, A.; Rice, P.M.; Hughes, B.; Smant, M.; Yang, S.-H. Giant tunnelling magnetoresistance at room temperature with $\mathrm{MgO}$ (100) tunnel barriers. Nat. Mater. 2004, 3, 862-867.

7. Vuoristo, P.; Mantylä, T.; Kettunen, P. Adhesion and structure of $\mathrm{rf}$ sputtered magnesium oxide coatings on various metal substrates. J. Vac. Sci. Technol. A 1986, 4, $2932-2937$.

8. Costache, M.V.; Moodera, J.S. All magnesium diboride Josephson junctions with $\mathrm{MgO}$ and native oxide barriers. Appl. Phys. Lett. 2010, 96, 082508:1-082508:3.

9. Yamamori, H.; Shoji, A. Improvement of uniformity of NbCN/MgO/NbCN Josephson junctions for large-scale circuit applications. Supercond. Sci. Technol. 1999, 12, 877-879.

10. Sugiyama, K.; Akazawa, K.; Oshima, M.; Miura, H.; Matsuda, T.; Nomura, O. Ammonia synthesis by means of plasma over MgO catalyst. Plasma Chem. Plasma Process. 1986, 6, 179-193.

11. Nibbelke, R.H.; Scheerová, J.; de Croon, M.H.J.M.; Maroon, G.B. The oxidative coupling of methane over $\mathrm{MgO}$-based catalysts: A steady-state isotope transient kinetic analysis. J. Catal. 1995, 156, 106-119.

12. Chen, Y.; Sibley, W.A.; Srygley, F.D.; Weeks, R.A.; Hensley, E.B.; Kroes, R.L. Negative-ion vacancies in irradiated MgO. J. Phys. Chem. Solids 1968, 29, 863-865.

13. Freund, M.M.; Freund, F.; Batllo, F. Highly mobile oxygen holes in magnesium oxide. Phys. Rev. Lett. 1989, 63, 2096-2099.

14. Martinez Boubeta, C.; Beltrán, J.I.; Balcells, L.I.; Konstantinović, Z.; Valencia, S.; Schmitz, D.; Arbiol, J.; Estrade, S.; Cornil, J.; Martínez, B. Ferromagnetism in transparent thin films of MgO. Phys. Rev. B 2010, 82, 024405:1-024405:7.

15. Nitesh, K.; Sanyal, D.; Sundaresan, A. Defect induced ferromagnetism in MgO nanoparticles studied by optical and positron annihilation spectroscopy. Chem. Phys. Lett. 2009, 477, 360-364.

16. Ferrari, A.M.; Pacchioni, G. Electronic structure of F and V centers on the MgO surface. J. Phys. Chem. 1995, 99, 17010-17018.

17. Gu, B.; Bulut, N.; Ziman, T.; Maekawa, S. Possible $\mathrm{d}^{\circ}$ ferromagnetism in $\mathrm{MgO}$ doped with nitrogen. Phys. Rev. B 2009, 79, doi:10.1103/PhysRevB.79.024407.

18. Grob, M.; Pratzer, M.; Morgenstern, M.; Lezaic, M. Catalytic growth of N-doped MgO on Mo(001). Phys. Rev. B 2012, 86, 075455.

19. Moyses Araujo, C.; Kapilashrami, M.; Xu, J.; Jayakumar, O.D.; Nagar, S.; Wu, Y.; Århammar, C.; Johansson, B.; Belova, L.; Ahuja, R.; et al. Room temperature ferromagnetism in pristine $\mathrm{MgO}$ thin films. Appl. Phys. Lett. 2010, 96, 232505:1-232505:3.

20. Prucnal, S.; Shalimov, A.; Ozerov, M.; Potzger, K.; Skorupa, W. Magnetic and optical properties of virgin arc furnace grown $\mathrm{MgO}$ crystals. J. Cryst. Growth 2012, 339, 70-74. 
21. Gao, F.; Hu, J.F.; Yang, C.L.; Zheng, Y.J.; Qin, H.W.; Sun, L.; Kong, X.W.; Jiang, M.H. First-principles study of magnetism driven by intrinsic defects in $\mathrm{MgO}$. Solid State Commun. 2009, 149, 855-858.

22. Beltrán, J.I.; Monty, C.; Balcells, L.I.; Martínez-Boubeta, C. Possible d ${ }^{\circ}$ ferromagnetism in MgO. Solid State Commun. 2009, 149, 1654-1657.

23. Yu, H.K.; Lee, J.-L. Growth mechanism of $\mathrm{MgO}$ film on Si (100): Domain matching epitaxy, strain relaxation, preferred orientation formation. Cryst. Growth Des. 2010, 10, 5200-5204.

24. Martínez Boubeta, C.; Cebollada, A.; Calleja, J.F.; Contreras, C.; Peiró, F.; Cornet, A. Magnetization reversal and magnetic anisotropies in epitaxial $\mathrm{Fe} / \mathrm{MgO}$ and $\mathrm{Fe} / \mathrm{MgO} / \mathrm{Fe}$ heterostructures grown on Si (001). J. Appl. Phys. 2003, 93, 2126-2134.

25. Kapilashrami, M.; Xu, J.; Ström, V.; Rao, K.V.; Belova, L. Transition from ferromagnetism to diamagnetism in undoped $\mathrm{ZnO}$ thin films. Appl. Phys. Lett. 2009, 95, 033104:1-033104:3.

26. Kim, D.Y.; Hong, J.S.; Park, Y.R.; Kim, K.J. The origin of oxygen vacancy induced ferromagnetism in undoped $\mathrm{TiO}_{2}$. J. Phys. Condens. Matter 2009, 21, 195405:1-195405:4.

27. Hong, N.H.; Sakai, J.; Poirot, N.; Brize, V. Room-temperature ferromagnetism observed in undoped semiconducting and insulating oxide thin films. Phys. Rev. B 2006, 73, 132404:1-132404:4.

28. Hong, N.H. Magnetism due to defects/oxygen vacancies in $\mathrm{HfO}_{2}$ thin films. Phys. Status Solidi C 2007, 4, 1270-1275.

29. Li, J.; Jiang, Y.; Li, Y.; Yang, D.; Xu, Y.; Yan, M. Origin of room temperature ferromagnetism in MgO films. Appl. Phys. Lett. 2013, 102, 072406:1-072406:4.

30. Kapilashrami, M.; Xu, J.; Rao, K.V.; Belova, L.; Carlegrim, E.; Fahlman, M. Experimental evidence for ferromagnetism at room temperature in $\mathrm{MgO}$ thin films. J. Phys. Condens. Matter 2010, 22, 345004:1-345004:5.

(C) 2013 by the authors; licensee MDPI, Basel, Switzerland. This article is an open access article distributed under the terms and conditions of the Creative Commons Attribution license (http://creativecommons.org/licenses/by/3.0/). 